\title{
Spatially organized "vertical city» as a synthesis of tall buildings and airships
}

\author{
Olga Gagulina ${ }^{1}$, Sergei Matovnikov ${ }^{1}$ \\ ${ }^{1}$ Volgograd State Technical University, Volgograd, Akademicheskaya St., 1, 400047, Russia
}

\begin{abstract}
The paper explores the compact city concept based on the «spatial» urban development principles and describes the prerequisites and possible methods to move from «horizontal» planning to «vertical» urban environments. It highlights the close connection between urban space, high-rise city landscape and conveyance options and sets out the ideas for upgrading the existing architectural and urban planning principles. It also conceptualizes the use of airships to create additional spatial connections between urban structure elements and high-rise buildings. Functional changes are considered in creating both urban environment and internal space of tall buildings, and the environmental aspects of the new spatial model are brought to light. The paper delineates the prospects for making a truly «spatial» multidimensional city space.
\end{abstract}

\section{Introduction}

In the $20^{\text {th }}$ century, ultra-large cities became a unique phenomenon rather than simply vast living areas shared by huge numbers of people. The society living in large urban agglomerations proved most sensitive to social changes, while large cities themselves continued to evolve in line with the outdated architectural principles. The key problems, among which there were transport crisis and growing detachment between people or even hostility of cities to their inhabitants, were increasingly aggravating, and the attempts to resolve them using the then available planning techniques failed to improve the quality of life, causing further crisis situations. The compact city concept that surfaced yet in the $60 \mathrm{~s}$ of the previous century was among the first insights in the true needs of consumers. It was obvious that the city is to remain human-scaled and comfortable regardless of its size. Without slowing down their horizontal expansion, the cities started crawling upward. But a simple change in the plane and vector of growth was insufficient to reconcile citizens and cities. High-rise buildings offered by large cities and, in a sense, becoming their identity elements greatly simplified the settlement of growing population, but skyscrapers as they now exist turned into «ivory towers» ineffective in helping people interact with the city environment. In order to overcome this «isolation» and allow high-rise structures to be active participants of the city life, it is necessary not only to revise the architectural and urban planning principles and techniques, but also to consider the means for connection

\footnotetext{
${ }^{1}$ Corresponding author: o.gagulina@yandex.ru
} 
with the city plane and between parts of standalone buildings. The development and introduction of air transport would have become a step change in improving the functionality and appearance of large cities and resolved numerous problems faced by urban planners today and in the future.

The issues of organizing a new type compaction-focused urban environment and the aspects of high-rise construction discussed by such authors as J. Dancig and T. Saati [1], J. Jacobs [2], M. Jenkins, E. Burton, K. Wiliams, M. Brehani, N. Dempsey [3], P. Neuman [4], E. Mellows, J. Gehl, I. Lezhava [5], A. Golovin, A. Krasheninnikov [6], A. Magai [7, 8], as well as the emerging conceptual developments in the field of architecture and advanced transport service, formed the basis for this study aimed at rethinking the contemporary urban planning reality and fleshing out the prospects for spatial development of large cities aided by air transport.

Although aviation has long been in good and extensive use for long-distance communication, the use of air transport in the «body» of an urban settlement would seem exotic. Since the beginning of the 2000s, there has been a growing interest toward lighterthan-air vehicles. There are even a few concepts for the use of airships relevant in terms of municipal connections and architectural opportunities. Still, such projects and suggestions seem fantastic to most specialists. Transport is inseparable from the city life, just as city architecture, which is formed within the context of the city while shaping and determining its appearance. These three notions are so closely interconnected that they cannot be modified separately and require a holistic view. Each component of the «urban environment — architecture - transport» triad has an identical value and needs commensurate attention.

\section{Materials and Methods}

In a number of countries, the «new urbanism» concept has already been assigned a government policy status and become the basis for the modern urban development mentality. The core rule of compact cities is the intensive use of the existing city spaces, which explains their main «compact» characteristics.

First, this is the optimal density of development achieved through the use of various techniques and means, where the major role is that of tall buildings subject to their competent and multi-optional deployment.

Second, this is about building close connections between various parts of urban structure and improving the accessibility aspect.

Third, there is multi-functionality of each particular city district as well as the functional saturation of both the urban environment and buildings, while preserving the integrity of both a confined territorial unit and the city as a whole.

Fourth, there is a clear focus on environmental conservation and accessibility of natural resources for citizens.

The optimal density, according to most urban planners, can be achieved through the even spread of population over the city territory excluding overpopulated or underpopulated areas, coupled with a gradual transition from the highest-density city center to the more discrete periphery. 


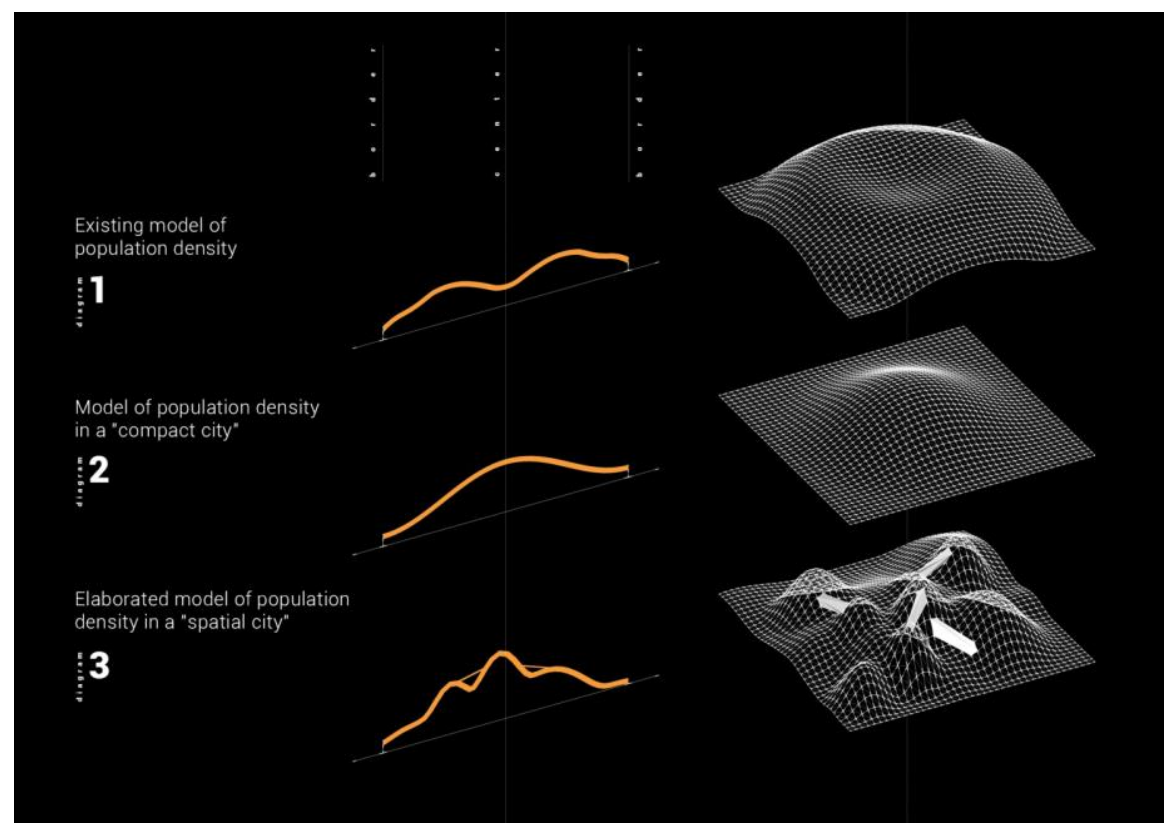

Fig. 1. Density of settlement in various urban organization models

The first diagram shows a «conventional model» with the core slightly «subsiding» in terms of the population density. The core part accommodates various «centers»: office spaces, shopping malls, cultural and administrative facilities surrounded by a vast residential area with so called «dormitory» communities. This structure, based on the functional zoning principle, presents the «variable concentration» scenario. Because the bulk of population live outside the city center and use it as a platform for work, study and leisure, the periphery remains «empty» for the greater part of the day. This model is characterized by the presence of areas with a nearly zero density - extensive park areas or abandoned industrial facilities if located within the city limits. The second diagram demonstrates the principle for building a «compact» model, which can be defined as a principle of uniform concentration. The concentration refers to all aspects - residential space, social functions and spaces, as well as resources. The degree of concentration is high, and its percentage varies negligibly in all areas. The system of strict functional zoning associated with «daily commute» of citiziens is turned away. The third diagram depicts the suggested concept featuring a sophisticated structure with a transition to the «spatial» model based on the «compact city» principles, but adopted for ultra-large municipalities (megapolises) subject to the use of public air transport (airships). This model, as well as the «compact» one, eliminates «complete sparsity» and «empty zones», but allows for certain gradation with reasonable «surges» leading to higher concentrations, and «admissible sparsity» zones. In turn, «higher concentration» zones may have additional spatial connections and allow for certain "variability» of the daily concentration. The last model suggests the blending and smooth coexisting of the two previous models to form a new flexible and utterly variable urban organization pattern. It avoids negating the predecessors, and is rather based on the principle of adapting all the preceding experience, taking into account the specifics and differences of organizing cities with various population sizes.

While criticizing the rigid planning structure and framework in which «conventional» urban planners were trying to arrange the life of citizens, the second model also tries to offer its own scenario, undoubtedly more democratic and humane, stemming from a deep 
analysis and relying on a solid array of consumer data, but still «common for all» even if fairly flexible. The «compact city» concept does not employ a rigid framework and facilitates diversity in creating urban environments, but sets the clear «preferences». For example, a priority in urban development is placed on low and medium-rise buildings of various types. Gigantism in all its forms is alien to both «new urbanism» and «compact city» concepts which became synonyms. The compact deployment is seen not only in the insightful urban planning solutions, but also in the architectural style. A human being, who according to Le Corbusier's modular has become the measure of all things in urban planning, sets the scales on all levels of environmental organization. This is why sky scraping appears almost barbarian when applied to people and their habitat. Today, tall buildings, which are not a guarantor of «correct» compactness, often become an object of architectural and social criticism $[8,9]$.

Many urban planners have come to see tall buildings as one of the major architectural and social threats rather than an efficient settlement arrangement. Thus, the Dutch architect Jan Gehl underlines the extremely negative, in the social respect, architectural elements of skyscrapers [10]. This is first of all isolation, both with regard to other people and the city as a whole. Isolating people from the neighborhood and the city life, skyscrapers provoke detachment and cause social differentiation. The «closed» system of high-rise buildings does not help to extend social contacts and deforms the basic urban life ideas for their inhabitants. The ultra-large scale basically falls outside the pedestrian's perception. A significant concentration of skyscrapers in one area disorients and creates a feeling of a human-alien space. By changing the prevailing approach to urban planning and deploying tall buildings within city space it is possible to at least neutralize the negative aspects as described above.

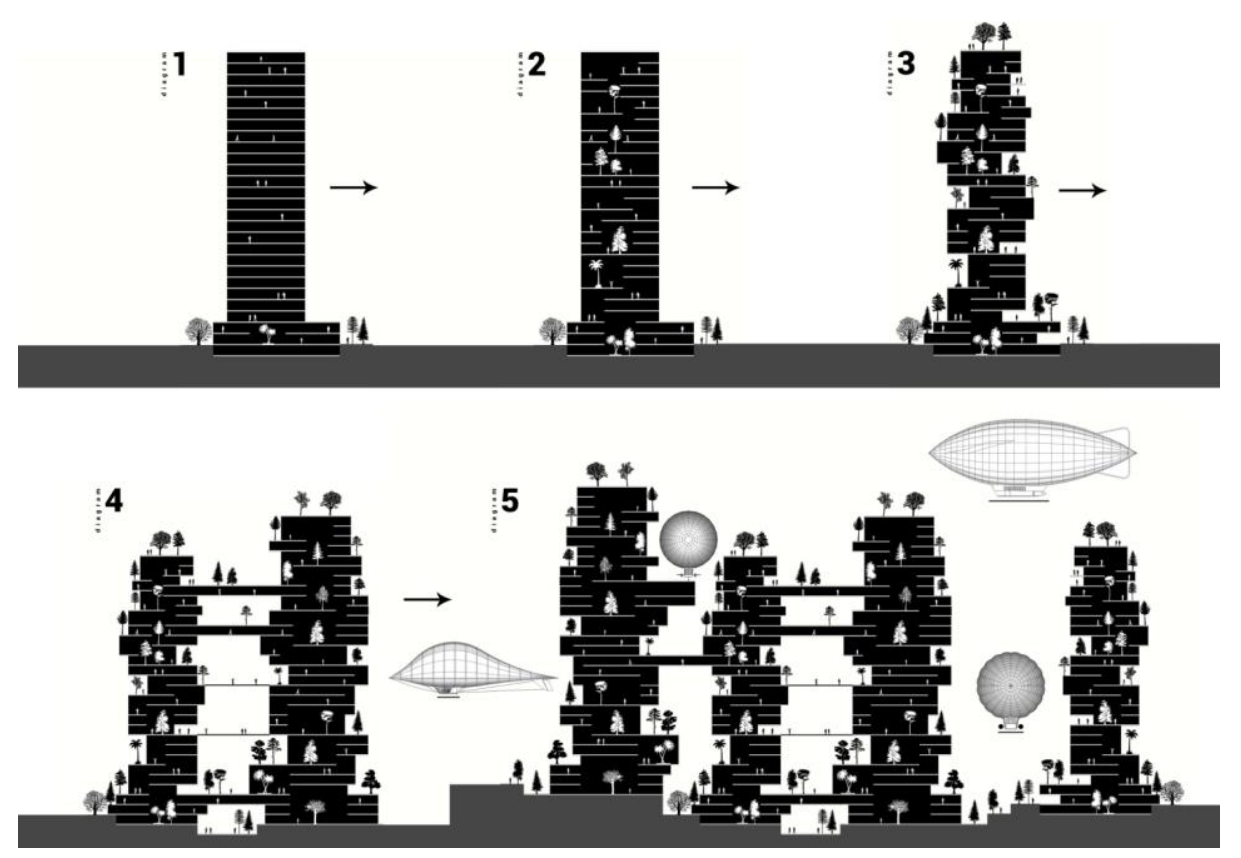

Fig. 2. Evolution of the structure of high-rise buildings

Figure 2 shows the transition from strictly floor-by-floor planning to the «vertical spatial city» system. Even now many projects forbear strict level-based division when a person living in the first floor can use the inner vertical transport to reach the required floor 
and avoid interacting with the «bulk» of the building (first diagram). The elaborated structure of the internal space allows organizing platforms for social interaction, use of new functions and getting more diverse visual impressions (second diagram).

A more sophisticated internal organization, penetrating through the structural boundaries of a tall and mainly «smooth» building, imparts the necessary amount of «porosity» by providing open zones inside the building normally used for green spaces. This allows creating additional social platforms and differentiating the configuration of tall buildings, but more important, combining the outer (urban) environment with the inner building space. As a result, there is a certain effect of blurring boundaries between architecture and the surrounding space. Such belts and areas inside buildings stimulate the search for new engineering, structural and architectural solutions changing the appearance and image of tall buildings (third diagram).

The comprehensive approach to urban development envisages «ensembles» of high-rise structures in contrast to stand-alone skyscrapers [11]. Despite having functional and visual cohesion, buildings may still need «hardwired» structural ties (fourth diagram). Various functional bridges and passages, as well as certain protruding parts of buildings, when mutually connected, encourage people traffic and provide additional access to nearby structures.

The use of airships to provide «movable» non-structural links between buildings and the ground can help integrate separate structures into a common spatial environment. Air transportation between various points of this environment located at various heights will form a sort of «spatial» streets. «Infusion» of urban environment in buildings will make the city truly spatial (fifth diagram).

In compact cities, all principal objects being the gravity points of everyday life, are to be within easy reach. Reaching all key targets should not take more than half-an-hour. The intrinsic urban planning criteria are quick relocation and enhanced mobility. Cities employing the new urbanism ideology set their sights on the new means of transport [12]. The introduction and development of a municipal network of airships could allow connecting any points of the city landscape. Modern airships materially differ from their predecessors thank to suspension in the air and precision navigation. Airships do not need clumsy and complex mooring structures any longer. With their new capabilities, they could be «moored» to the existing structures, while mooring systems and light mooring structures could be integrated with tall buildings.

Such architectural projects appeared already in the beginning of the previous century. This brings to mind the images of one of the first landmark skyscrapers - Empire State Building with an airship moored to its spire. Similar ideas were promoted by the Russian architect Ivan Leonidov. The blueprint prepared by the People's Heavy Industry Commissariat in 1934-1936 featured an airship site on the roof of one of the towers. The prototypes of the modern concepts of «soaring» skyscrapers can be seen in the works of G. Krutikov and I. Iozefovich [13]. These projects remained utopia, but the technologies for engineering both airships and tall buildings have taken a huge step forward, and the $21^{\text {st }}$ century already saw an array of new diverse concepts. The most renowned system of airships is Airbia of Aleksandros Tsolakis and Iren Shamma designed for carrying passengers from suburban homes to city centers [14]. This concept is set to support air transportation between various parts of the city environment helping to extend communication to its remote areas.

Due to their ability to lift and accommodate a large number of passengers, airships, along with their immediate transportation function, can play a role of mobile architecture. A whole segment of soaring buildings and structures relies on the use of various type airships. For example, the «Hydrogenase» project of the architect Vinsent Callbaut has a clear environmental focus. He offers to create a soaring vertical space accommodating residential 
quarters, offices, scientific laboratories, manufacturing centers, as well as gardens and plantations of green macro-algae producing bio-hydrogen as the main fuel for airships. The examples here illustrate a sustained interest in the air as a potential space for future urban development.

The integration of transport and city structures will transform the conveyance function from a regional «dictator» into an «option» adjusted and catered for the needs of citizens.

In order to avoid making each standalone high-rise building an isolated «city in the city», it is important to balance the functional distribution between the open «street» environments and «inner streets» built in large architectural objects. «Outer streets» penetrating and transfusing buildings should remain functionally and visually attractive to citizens.

The correct scale and structure of tall buildings, their specifically optimal height and competent functional filling, as well as the justified layout of skyscrapers in the city landscape will help to eliminate idle areas both inside buildings and within adjacent urban environments [15].

For many decades, the planning practice was building on the clear time and space differentiation of the key routine functions of people: work, dwelling, leisure [16]. These totally separated functional pieces were «attached» to the common social center. The elimination of this marked structuring and the blurring of functional boundaries have also led to «diffuse» the center and create a polycentral planning system [17].

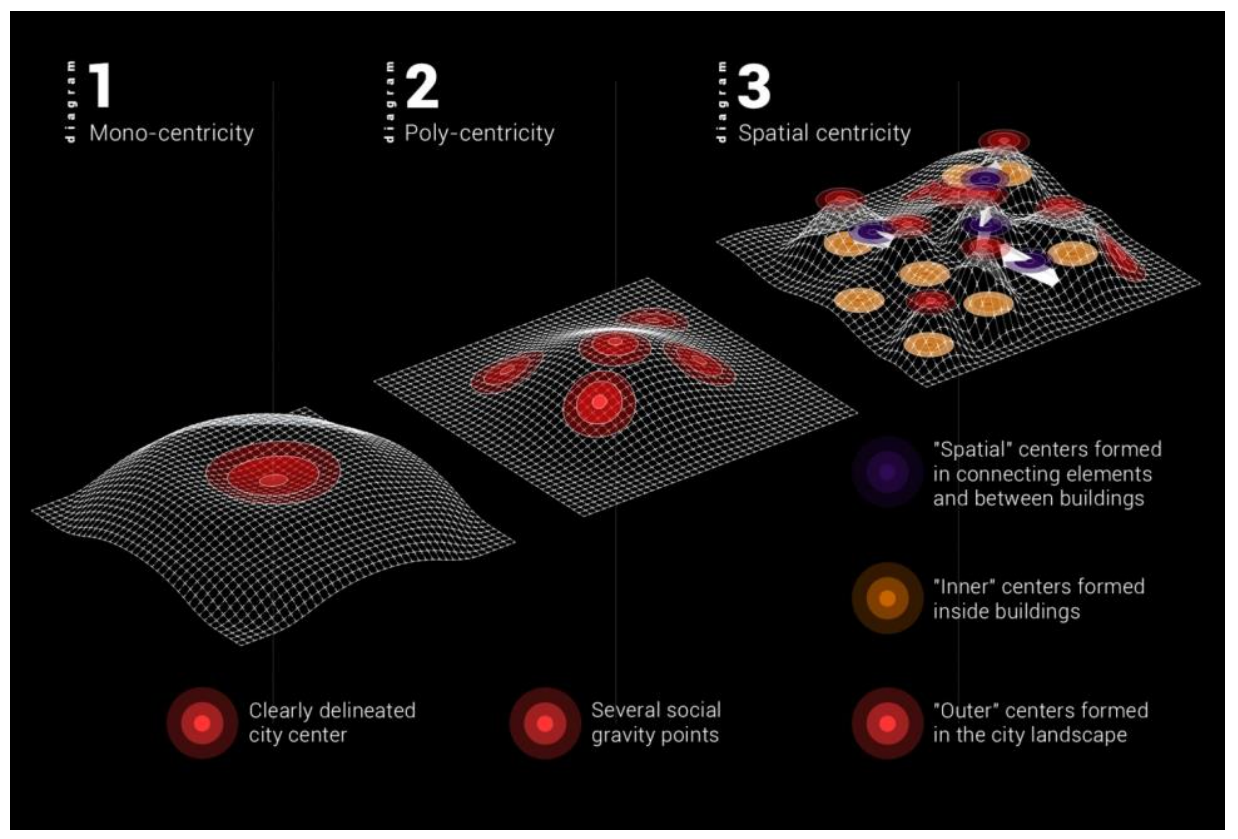

Fig. 3. Distribution of social centers in the city structure

Figure 3 illustrates the transition from a single-core structure to a system of a few city gravity centers evenly distributed within the city limits. The next stage can include, along with elevating the «street» and its partial lifting from the ground, the transfer of «social magnets» associated solely with the «street» to the inner space of buildings built in accordance with the urban development system. With the appearance of social centers developing both horizontally and vertically a spatial poly-centricity model can be 
developed. The special «porous» structure of buildings will create platforms existing at the junction of architecture and city environment (third diagram).

Similarly to functional diversity inside confined city areas, the internal structure of new tall buildings should combine functions without clearly dividing them by levels or zones. High-rise buildings and skyscrapers should not become living areas for a specific class of citizens only, as they can encourage good communication between neighbors and social interaction of people with different status and level of income.

New type high-rise buildings, developing the new urbanism theory, can encompass, in addition to the traditional forms, essentially different functional zones: residential, cultural and educational, «agricultural», industrial etc.

Caring for the environment has long stopped being just a popular trend and turned into an understanding that sustainable development is an integral part of urban planning. As such, solutions concerning the distribution of «green spaces» in large and ultra-large cities are of great importance no less than the transport regulation or settlement system. Great successes achieved in developing the vertical gardening technology will allow replacing idle park areas to follow the compact trend. The transfer of parks inside buildings, the system of diffused green spaces available not only in the city, but as far as possible everywhere inside high-rise buildings and accessible by everybody will make «nature» closer to people. Being so handy, elements of natural environment can serve as objects of closer and more frequent contact for megapolis inhabitants. A bright example of such continuous interaction is the Bosco Verticale skyscraper in Milan offering yet another example of vertically organized environment — «Vertical Forest» [18]. Such projects can be efficient environmental conservation tool on densely populated grounds.

One should remember that high-rise construction has a significant environmental impact [8]. The negative aspects associated with tall buildings, in particular, the behavior of air masses near buildings and insolation of the adjacent territory, make this type of construction an object of thorough analysis and balanced deployment [19].

Avoiding extensively spread urban districts with discrete development will also help to draw urban territory closer to the natural environment. The use of airships for transportation not only between city parts, but also beyond their limits will improve communication between urbanized and natural territories.

\section{Results}

The research conducted by the authors has revealed that the compact city concept should be adjusted in line with the previous urban development experience. To ensure efficient functioning of a city, today and in the future, it is necessary to switch from a flat planning model to the spatial system.

The spatial organization of a city structure requires the consideration of a vertical layout of city environment, including vertical streets, gardens and squares.

In this vertical context, a special part will be played by high-rise construction. Buildings of a «spatial city», instead of being closed systems, will become a part of the city landscape and allow for «penetration» of some functions, spaces and elements inside them. High-rise structures should be built following the same principles as the «street» city environment. The city and its buildings should become a single architectural and structural organism.

Spatial transport connections can be built using the public air transport system. Mooring structures for airship network, being integrated with high-rise structures, will allow moving «from building to building» and provide immediate access to the ground level and to social spaces placed at a certain height. 
Additional transport connection will help to avoid «conservation» of people inside autonomous buildings, given a competent and versatile functional arrangement of territories and spaces «inside» and «outside» them.

In order to improve the city compactness and natural resources accessibility for residents of high-rise structures, it is necessary to develop vertical gardening technologies for buildings and structures. Also, an efficient tool for providing closer ties between urbanized territories and the natural environment as one of the components of a sustainable city development is the use of environmentally friendly air transport (airships).

\section{Discussion}

The earlier studies of various authors in the field of high-rise architecture considered not only technical aspects but also problems of integration of high-rise buildings into the existing urban environment. In turn, the theoretical foundations of modern urban planning concepts try to avoid super-large vertical settlement, treating it as an inhumane way of organizing urban and architectural environments. The presented work makes an attempt to remove this contradiction and identify the directions of changes in urban planning systems, means of transport communication and high-rise construction.

The researched showed that in the issue of the formation of large-scale urban education, one should not only unite and reconcile the past practice of territorial planning but also come up with truly innovative solutions in the environmental organization. Such a decision can be a transition to a system of spatial movement and formation of territories and spaces of social interaction, and not only on the plane but also on various elevations and levels. The life and principles of the organization of large cities can (and perhaps should) be different from their less densely populated counterparts. Spatial development will contribute to the formation of the specifics of the environment conditioned by the necessity of living together and the constant social interaction of a large number of people.

The verticality of certain areas and some urban processes multiplied by the system of spatial transport links will

- solve many urban problems;

- more compactly accommodate the numerous residents of large cities'

- provide increased mobility;

- help to change the idea of a super-large scale of architecture considered now as something "frightening," "alien" and "enslaving."

The introduction of air transport will not only promote spatial communication but also solve the problem of organizing roads, partially unload urban traffic and, most importantly, help in mastering the air environment and adapting it to the needs of residents.

Polyfunctionality of both external environment and internal space of buildings, as well as the functional mobility, will make the city interesting and comfortable for each citizen. In turn, the development of the vertical distribution system of green plantations can change the idea of megacities as stone jungles with scanty vegetation and large park oases, the scale and value of which is sometimes difficult to assess because it is quite hard to visually cover the horizontal green areas. Also, the air transport network, which helps residents of metropolitan areas move relatively quickly and comfortably from a densely populated large city to areas of natural wild or less dense urban formations, can eliminate the feeling of detachment from natural resources.

To develop and implement the concept of a modern spatial city, it is necessary not only to change the skeptical attitude towards the issue of the ubiquitous use of air transport but also conduct a number of additional studies on the effective interaction of the principles of the new urbanism and modern methods of organizing of the high-altitude construction and vertical settlement. 


\section{Conclusions}

One can certainly state that, by changing the existing image, high-rise construction can be an effective way of forming a stable, humane and diverse in its structure living environment. Together with the air transport system, high-rise buildings transform the flat structure of city into a volumetric one. However, the nature of the human and society is such that both the individual and the society are afraid and resist to global changes. In this respect, the concepts of the "new urbanism" and the "compact city" in their simplified form create around the person the most comfortable world, a kind of modernized semblance of ancient European cities, but with the support of the latest technologies. However, the metropolis is not a place of silence and sleepy comfort but rather a territory of challenges. The big city has always become a platform for the birth of revolutions, namely architectural, transport, technological and social. This is its main feature, which should be maintained and stimulated at all levels of urban planning.

Soaring skyscrapers and flying vehicles, which now exist only in literary fiction and cinema, still look like rather naive dreams than practical solutions to problems of settlement and urban organization, although some of the technologies exist today. However, the limitedness, depletion and high value of land plots push city planners and architects towards fresh, creative, not mundane solutions.

Spatial urban development, which is based on high-altitude architecture and air transport, will make urbanized areas truly compact. A smart growth of urban education in modern realities is not about the universal verticalization of construction but rather the appearance of a multitude of vectors for its spatial development.

\section{References}

1. J. Jacobs, The Death and Life of Great American Cities (Moscow, New Publishing house 2011)

2. M. Jenks, N. Dempsey, Future Forms and Design for Sustainable Cities Routledge 444 (2005)

3. M. Neuman, The Compact City Fallacy Journal of Planning Education and Research 25, 11-26 (2005)

4. G. Lezhava, Modern architecture and city. Academia. Architecture and construction 4, 5-14 (2014)

5. A.V. Krasheninnikov Town-planning development of the housing estate Research of experience of the western countries (Moscow, Architecture-S 2005)

6. A. Magaj High-rise buildings as the vertical integrated inhabited environment, Bulletin of the construction equipment, 6, 64-65 (2016)

7. A. Magaj, Modeling of functional structures of high-rise buildings. Housing construction 12, 1-5 (2016)

8. URL: www.asrmag.ru/article/vysotnye-zdaniya/ (last accessed 2017/08/05)

9. V. Korotich Image of modern high-rise architecture, Academic messenger UralNIIproekt RAASN, 3, 36-39 (2011)

10. J. Gehl, Cities for People, (Island Press, 2010)

11. P. P. Zueva, The high-rise building in the urban environment. Proc. of the Conf. Topical problems of construction, ecology and energy saving in the conditions of Western Siberia 98-104 (Russia, Tyumen, 2014) 
12. D. Ju. Lomakina, Spatial concepts and images of the future in degree projects on town planning. All-Union research institute of problems of scientific and technical progress of information in construction 4, 42-55 (2015)

13. N. A. Saprykina, Development of the concept of mobile architecture: the flying objects. Architecture and modern information technology, 34 1, 1 (2016)

14. URL: www.airbia.wordpress.com/2010/01/22/airbia-a-suburban-airship/ (last accessed 2017/08/15)

15. O. M. Shencova, High-rise buildings in the volume and spatial urban environment. Architecture. Construction. Education, 7, 1, 102-110 (2016)

16. D. S. Parygin, New urbanism in the large industrial city, Regional economy: theory and practice, 38, 35-40 (2013)

17. F. Dieleman, M. Wegener Compact City and Urban Sprawl, Built Environment, 30(4), 308-323 (2004)

18. URL: $\quad$ www.archdaily.com/777498/bosco-verticale-stefano-boeriarchitetti (last accessed 2017/08/17)

19. S. V. Nikolaev, High--Rise Manual: Typology and Design, Construction and Technology (Moscow, Atlant-Stroy 2006) 